\title{
A hora e a vez da estrela: um estudo comparativo entre as obras de Guimarães Rosa e Clarice Lispector
}

\author{
Marcos Aurélio Souza ${ }^{1}$
}

\begin{abstract}
No Sertão a pedra não sabe lecionar, e se lecionasse, não ensinaria nada; lá não se aprende a pedra: lá a pedra, uma pedra de nascença, entranha a alma.

João Cabral de Melo Neto (A Educação pela pedra, 1968, p. 11)

Como uma cascavel que se enroscava, A cidade dos lázaros dormia... Somente na metrópole vazia Minha cabeça autônoma pensava.
\end{abstract}

Augusto dos Anjos (Obra Completa, 1994, p. 236).

Um estudo, que se propõe comparativo, das obras de Guimarães Rosa e Clarice Lispector, poderia ser desenvolvido com certo desembaraço, numa perspectiva da história da literatura brasileira consagrada, o que atribuiria a esses escritores, por exemplo, epítetos mais ou menos consensuais, como os de autores psicológicos ou egóticos da chamada geração de $45^{2}$. Entretanto, o que parece fácil descamba, muitas vezes, na estéril sistematização, no reducionismo, na excessiva superficialidade ou, quando não raramente, no equívoco. Instrumentalistas ou egóticos foram também, por exemplo, escritores como Graciliano Ramos, Machado de Assis e Osman Lins, fato que por si só não os incluem numa geração ou num "espírito de época", o Zeitgeist tão propalado pelo romantismo alemão no século XIX.

É forçoso saber que, ainda publicando numa mesma época e às vezes, num mesmo ano, como é o caso de O Lustre e Sagarana (ambos de 1946), seus respectivos autores, Clarice Lispector e Guimarães Rosa, possuem tantas afinidades quanto diferenças entre si, fato que se daria, também, se cada um deles fosse comparado a qualquer outro escritor de época ou período diferente. O que poderia parecer um início esclarecedor, desse meu estudo, problematizaria ainda mais a ideia de uma comparação, se não fosse a opção de comparar, não com o fim de encontrar similaridade pela

\footnotetext{
${ }^{1}$ Professor Adjunto da Universidade do Estado da Bahia - Campus I.

${ }^{2}$ Em História Concisa da Literatura Brasileira (São Paulo: Cultrix, 2000, p. 435) Alfredo Bosi, percebendo a dificuldade de colocar os dois escritores numa mesma "geração" escreve: Sentimos as diferenças em relação à prosa dos pós modernistas maiores (Guimarães Rosa e Clarice Lispector), mas não sabemos com precisão onde desenhar a linha do corte. Talvez porque o corte se tenha dado em mais de um nível.
} 
similaridade ou a diferença pela diferença, mas comparar para descrever, compreender e apreciar mais a obra fascinante desses dois escritores brasileiros.

Entendendo, dessa forma, o ato poético como forma autônoma, independente da arbitrariedade de uma sistematização literária, ou como afirma Bachelard (1993, p. 1) "sem um passado próximo ao longo do qual pudéssemos acompanhar sua preparação e seu advento", o presente estudo se concentrará, principalmente, em duas obras significativas ${ }^{3}$, o conto $A$ bora e ver. de Augusto Matraga, constante no livro Sagarana de Guimarães Rosa, publicado, como já referi, em 1946, e o romance $A$ hora da Estrela de Clarice Lispector, cuja publicação se deu em 1977. A proposta é mostrar, através da narrativa, urdida por esses escritores, o embate existencial dos seus personagens, os quais, ao buscarem seu momento de plenitude, a sua hora e vez (como veremos adiante), encontram no meio, no sertão ou na cidade, respectivamente, elementos importantes para a própria configuração desse embate.

Inicialmente, é interessante observar que nas duas obras, há um estranhamento de seus narradores em relação ao próprio ato de contar, ambos colocam em questão a invenção como algo mais impactante do que a própria realidade, ou como diria Mário Vargas Llosa, como a verdade das mentiras, já que "nos comunicam verdades fugidias e evanescentes que escapam sempre aos descritores científicos da realidade 4 (1990, p. 15). Nesse sentido, é que o narrador, Rodrigo S. N, em $A$ hora da estrela registra: "o que escrevo é mais do que invenção, é minha obrigação contar sobre essa moça entre milhares delas" (p.13). Por sua vez, o narrador de Matraga irrompe, ao falar do retiro de Matraga, com a afirmativa de que "se passaram pelo menos seis ou seis anos e meio, direitinho deste jeito, sem tirar e nem por, sem mentira nenhuma, porque esta aqui é uma história inventada, e não é um caso acontecido, não senhor.” (p.348).

A ideia de uma história inventada, que poderia provocar descrédito por ser, justamente, uma criação, ou uma "mentira" bem contada, motiva aos seus narradores investir seus textos de determinadas qualidades poéticas, necessárias para que o leitor, mesmo alertado sobre esse jogo ficcional, ou sobre essa "invenção", reflita, atenciosa e especialmente, sobre o drama singular dos seus protagonistas. São essas qualidades poéticas que aproximam as obras de Clarice Lispector e Guimarães Rosa, ao cientificar o leitor do processo inventivo, da "mentira", eles acabam por capturá-lo, pela linguagem poética.

Uma dessas qualidades poéticas dos textos de Clarice Lispector e Guimarães Rosa é o processo inicial de esvaziamento do personagem e da situação centrais para em seguida, ressignifícá-los pela trama que assume seu “direito de significar”. Uma espécie de redução do ser

\footnotetext{
3 As citações dessas obras virão indicadas apenas com o número da página.

${ }^{4}$ Tradução minha do espanhol para o português.
} 
até o limiar do não-ser, para depois fundá-lo pela linguagem que propõe um estranhamento das mínimas coisas, engrandecidas pelo sentido íntimo da observação poética. Assim é que o narrador de Clarice Lispector começa a história de Macabéa, uma nordestina deslocada no ambiente citadino, desprovida de importância na realidade excludente do Rio de Janeiro:

\begin{abstract}
Mas a pessoa de quem falarei mal tem corpo para vender, ninguém a quer, ela é virgem e inócua, não faz falta a ninguém (...) Como a nordestina, há milhares de moças espalhadas por cortiços, vagas de cama num quarto, atrás de balcões trabalhando até a estafa. Não notam sequer que são facilmente substituíveis e que tanto existiriam como não existiriam. Poucas se queixam e que eu saiba nenhuma reclama por não saber a quem. Esse quem será que existe? (p. 14)
\end{abstract}

Em Sagarana, a estratégia de esvaziamento e ressignificação parece perpassar por quase todas as histórias. No conto "Burrinho pedrês", só depois de tornar vazia a figura do pobre ruminante, que se não bastasse sua condição de besta, também é velha e doente, o narrador passa a descrever sua bela odisséia no Vale do Rio das Velhas, Turíbio Todo, personagem marginalizado e descrito, em "O duelo", como "papudo, vagabundo, vingativo e mau", tem sua história engrandecida pela fuga e pela vingança. É estranho, doentio, vazio e seco, assim como são seus dois lúgubres habitantes, o ambiente dos primos da Sarapalha, até o momento de remonte do passado. Mas é em $A$ bora e a vez de Augusto Matraga, a exemplo de $A$ bora da estrela, que esse esvaziamento passa a se configurar como momento latente para um questionamento maior, um desejo de existir, pelo menos em algum momento da vida. Há uma necessidade, nesse ponto, de mostrar que os protagonistas dessas histórias, a princípio não são nada ou pelo menos não possuem grandeza alguma, para depois revelar-lhes em determinada hora: sentido, sentimento, significação, já que "Matraga não é Matraga, não é nada" (p. 329) e Macabéa "tinha sem o saber o vazio que enche a alma dos santos (...) sua vida era uma longa meditação sobre o nada.” (p. 38).

A percepção desse nada, ou do esvaziamento, longe de significar algo negativo, no sentido da imobilização total da vida e do sentimento, permite aos narradores caminhar com certa paixão em direção ao interior dos seus personagens e dos ambientes que os cercam, pois, segundo Chevalier e Gheerbrant:

Esvaziar-se, no sentido simbólico que os poetas e místicos dão a essa expressão, significa libertar-se do turbilhão de imagens, desejos e emoções; é escapar da roda das existências efêmeras pra só sentir a sede do absoluto (...) ao dizer vazio (ou nada), abolição, negação, desnudamento, designam-se uma realidade em ato, ainda intensamente vital, a atuação suprema pela qual se consuma o vazio... (2002, p. 932).

Contribui para esse processo de esvaziamento, fundamentalmente, a grandeza exasperadora do ambiente em que se encontram os personagens, tanto o sertão de Matraga, quanto a cidade de 
Macabéia. Todos os elementos evocados desses lugares parecem interagir com o drama particular de seus viventes, dessa forma, mais do que simples espaços, sertão e cidade passam a ser valor, estado de alma. Pois "mesmo quando um poeta menciona uma dimensão geográfica, sabe por instinto que essa dimensão é lida localmente porque enraizada num valor onírico particular." (BACHELARD, 1993, p. 192). Seja no cosmopolitismo citadino ou nas veredas do sertão, há sempre, por parte da escrita de Guimarães Rosa e Clarice Lispector, a tentativa de demonstrar uma espécie de conspiração da mecânica natural ou artificial do meio para que a história se torne cada vez mais intensa e mágica.

Deslocado da sua condição ou da sua identidade de macho, provedor da família, por não possuir mais certo poder aquisitivo, e também diminuído, enquanto ser humano afetivo, por não conseguir estabelecer um bom relacionamento com mulher e filha, Matraga procura os ambientes mais propícios para tentar, de alguma forma, não perder a sua virilidade e "brabeza", talvez a única coisa que lhe resta:

Ia indo em busca de qualquer luz em porta aberta, aonde houvesse assombros de homens, para entrar no meio ou desapartar (...) E, em casa, sempre fechado em si. Nem com a menina se importava. Só. No mais, sempre com os capangas, com mulheres perdidas ou que houvesse de pior. Na fazenda - do Saco-da-Embira, nas Pindaíbas, ou no retiro do Morro Azul - ele tinha outros prazeres, outras mulheres, o jogo do truque e as caçadas (p.333-334)

Na verdade, todos esse lugares, assim como, o arraial da Virgem Nossa Senhora das Dores, como o Beco do Sem-Ceroula, "onde gente séria entra mas não passa” (p.332), possuem certa autonomia, esvaziam-se, quando Matraga passa com seu descompasso e seu desconsolo, com sua fúria e sua crueldade. E até o lugar onde ele impõe o seu passo bruto, parece exigir certo ritmo aos passantes: "Nhô Augusto desceu a ladeira sozinho - uma ladeira que a gente tinha de descer quase correndo, porque era só cristal e pedra solta (p. 333).

Topograficamente, a caminhada de Matraga pelo sertão é acidentada como sua história, são ladeiras íngremes, ribanceiras, caminhos e descaminhos, um vai e vem e um desce e sobe labiríntico, como a própria vida do personagem. As descidas, aliás, são as mais terríveis, por isso não é à toa que ele recebe a intimação de sua mulher, motivo pelo qual toda tensão é gerada, ao descer de uma ladeira, e também não é à toa que, após ser quase morto pelos capangas do seu rival, despenca de uma ribanceira terrível. O movimento de descida ou de queda significa também a abertura para uma situação crítica da história: de tensão, purgação dolorosa e renascimento. Reduzido mais uma vez à condição de nada ou de quase nada, com o corpo todo picado de faca e cheio de chagas profundas, provocadas pela queda, Matraga tem pelo menos sua vez de renascer das cinzas como uma Fênix. Novamente, é o esvaziamento que propiciará a ressignificação. Deixando o mundo 
para trás, ou lá em cima, é possível repensar sua vida, pois como o velho negro falou: "Os outros não vão vir aqui, para campear defunto, porque a pirambeira não tem descida, só dando muita volta. E, como tem um bezerro morto, na biboca, lá de cima vão pensar que os urubus vieram por causa do que eles estão pensando... (p. 342)".

Outra referência topográfica é a encruzilhada que aparece, duas vezes nos contos, em momentos decisivos. E como sabemos:

\begin{abstract}
A importância simbólica da encruzilhada é universal. Liga-se à situação de cruzamento de caminhos que converte numa espécie de centro do mundo. Pois, para quem se encontra numa encruzilhada, ela é nesse momento, o verdadeiro centro do mundo. Lugares epifânicos (i.e., aqueles onde ocorrem aparições e revelações) por excelência, as encruzilhadas costumam ser assombradas por gênios (ou espíritos), geralmente temíveis, com os quais o homem tem interesse em se reconciliar (...) (CHEVALIER, 2002, p. 367)
\end{abstract}

Em A hora e vez, de Augusto Matraga, a encruzilhada é esse encontro com o destino inexorável. $\mathrm{Na}$ primeira encruzilhada apresentada no conto, início da desgraça de Matraga, Dionora, sua mulher, o abandona de vez, fugindo com seu Ovídio Moura, sem antes, é claro, receber a admoestação aziaga do Quim recadeiro: "Volta para trás, minha patroa, que o caminho por aí é outro”. Para completar, Matraga recebe a notícia da fuga numa situação nem um pouco favorável à sorte. Pois:

Quando chega o dia da casa cair - que, com ou sem terremotos, é um dia de chegada infalível - o dono pode estar: de dentro, ou de fora. É melhor de fora. E é a só coisa que um qualquer-um está no poder de fazer. Mesmo estando de dentro, mais vale todo vestido e perto da porta da rua. Mas, Nhô Augusto, não: estava deitado na cama - O pior lugar que há, para se receber uma surpresa má. (p. 337)

São, em outro sentido, os cruzamentos, agora da metrópole carioca, que movem o destino de Macabéa, a protagonista deslocada em $A$ hora da estrela. Concomitantemente, o narrador observa com atenção a figura de uma mulher perdida e solitária e a dinâmica de um ambiente também em intenso deslocamento. Rodrigo S. N começa a problematizar personagem/ambiente numa cena que lembra $A$ une passant de Charles Baudelaire, "mas em vez do breve encontro com relampejante promessa de felicidade, aqui se encontra a perplexidade" (NITISHACK, 2004, p. 216): "É que numa rua do Rio de Janeiro peguei no ar de relance o sentimento de perdição no rosto de uma nordestina (p. 12).

É na cidade inconquistável, na urbe natal do desconsolo, como assim chamava o poeta Augusto dos Anjos, que Clarice Lispector constrói o desencontro de um ser fragilizado e vazio, com uma urbanidade também frágil e vazia. Ao contrário do sertão, ambiente naturalmente hostil, o Rio de Janeiro é tão artificial quanto a nordestina datilógrafa que gostava de Coca-cola. 
Todos se perdem na cidade, mas alguns, ao contrário de Macabéa, conseguem entender seu dinamismo caótico, sua natureza irracional e entram no jogo ciclônico das identidades, do anonimato e da artificialidade das relações. Como afirma Boa Aventura de Souza Santos (1997, p. 81) a cidade: “É uma zona híbrida, babélica, onde os contactos se pulverizam e se ordenam segundo micro-hierarquias (...) Em tal zona são imensas as possibilidades de identificação e de criação cultural, todas igualmente superficiais e igualmente subvertíveis...".

Ao assumir uma identidade de datilógrafa, ainda que uma péssima datilógrafa, e de uma inveterada consumidora de Coca-Cola, Macabéa tenta dialogar com a cidade, criando, assim, uma identidade de convivência, assim como Matraga, dialogando com o ambiente, também não tem seu status de filho do Coronel Afonsão Estêves, das Pindaíbas e do Saco da Embira. Entretanto, enquanto o personagem rosiano vive um conflito existencial, solitário em seu próprio chão acidentado, Macabéa compartilha com milhares de desenraizados seu desencontro com a agressiva urbanidade, pois, segundo Sevcenko: "Todos que perdem as raízes estão condenados a perambular acelerada e indefinitivamente pela zona, a se tornarem portanto, eles mesmos, zonas" (SEVCENCO, 1994, p. 34).

“A nordestina se perdia na multidão", solitária. E diferente da solidão desértica de Matraga, sua solidão era no meio das pessoas, dos pedestres, das prostitutas e das colegas balconistas das Lojas Americanas, espremidas num lúgubre quarto da periferia carioca. Condenada que era a ser zona, como as inúmeras zonas incomunicáveis da metrópole, o narrador tenta conectar Macabéa com outros espaços, outras pessoas. As zonas meretrícias, pareciam ser um caminho, já que é simbolicamente o terreno do desejo secreto e onde moças excluídas vendem o corpo, "única posse real” (13). Mas Macabéa “é virgem e inócua, não faz falta a ninguém”. Essa "verdade sexual do drama citadino" é, segundo Calligaris (1994, p. 92), um dos principais aspectos instigadores do impacto das cidades no homem moderno, pois, "um aspecto da urbanização, bem conhecido, é a ida à cidade de todo tipo de "desviante" sexual. As razões geralmente propostas são também conhecidas: o anonimato citadino e a própria concentração facilita os encontros (...) Não seria difícil então, entender por que a cidade é classicamente um lugar de deliquência; a oportunidade não faz o ladrão, ao contrário: ser ladrão é um jeito de se fazer valer, e a cidade é o lugar onde se trata de se fazer valer (de desejar desejos que, quem sabe, desejem o nosso desejo).

Não podendo interagir com a cidade, até mesmo com suas zonas mais abscônditas, Macabéa vive em seu quarto, esse espaço de intimidade e devaneio. Tanto que sua maior alegria foi, em determinado momento, gozar de um espaço só seu, gozar de uma solidão verdadeira, e não de uma "solidão multidão": 
Então, no dia seguinte, quando as quatro Marias cansadas foram trabalhar, ela teve pela primeira vez na vida uma coisa a mais preciosa: a solidão. Tinha um quarto só para ela. Mal acreditava que usufruía o espaço. E nem uma palavra era ouvida. Então dançou num ato de absoluta coragem (...). Dançava e rodopiava porque ao estar sozinha se tornava l-i-v-r-e! (...) Encontrar-se consigo própria era um bem que ela até então não conhecia. Acho que nunca fui tão contente na vida, pensou. Não devia nada a ninguém a ninguém e ninguém lhe devia nada. Até deu-se o luxo de ter tédio - um tédio até muito distinto. (p. 41-42)

Os personagens Matraga e Macabéa deslocam e são deslocados a espaços diferentes de ressignificação, mas tanto um como outro objetivam um momento de plenitude, um encontro com o significado da existência: a sua hora e vez. Esse encontro se dá, também, a partir de deslocamentos, uma fuga do outro, uma fuga de si. Da rua do Acre, na hora do crepúsculo, hora de ninguém, Macabéa parte para Olaria; seu destino era a predestinação de uma cartomante: o capim verde na porta da pitonisa moderna, dava-lhe uma tranquilidade inexplicável, a voz da moira engravida-a de futuro. Mesmo atropelada, Macabéa sonha e morre acreditando que sua hora chegou, seu momento de estrela.

Por sua vez, cavalgando no sertão, Matraga se deixa levar no trote indefinido de um jumento. Evitando o mesmo erro de Orfeu, ele não olha para trás, é também o seu momento, sua hora e vez. Seu caminho é definido pelo acaso, seu encontro é com a morte. Ao salvar toda uma família da chacina de Joãozinho Bem-Bem, uma certeza lhe permite sorrir, iria entrar no céu mesmo que fosse pela força.

Adaptados ou inadaptados ao lugar e às pessoas que os cercam, os personagens de Guimarães Rosa e Clarice Lispector interagem com seu meio em um diálogo que não raramente tem um final fatídico: na terra agreste ou no asfalto, gente e meio se confundem na hora e na vez do nada.

\section{REFERÊNCIAS}

ANJOS, Augusto dos. Obra Completa. Rio de Janeiro: Nova Aguilar, 1994.

BACHELARD, Gaston. A poética do espaço. São Paulo: Martins fontes, 1998.

CALLIGARIS, Contardo. Elogio da Cidade. In: PECHMAN, Robert Moses (org. e ap.) Olhares sobre a cidade. Rio de Janeiro: Ed. UFRJ, 1994.

CHEVALIER, Jean e GHEERBRANT, Alan. Dicionário de Símbolos. $17^{\mathrm{a}}$ ed. Tradução de Vera da Costa e Silva et al. Rio de Janeiro: José Olympio, 2002.

LISPECTOR, Clarice. A hora da estrela. Rio de Janeiro: Rocco, 1998. 
MELO NETO, João Cabral de. A Educação pela pedra. Rio de Janeiro: Sabiá, 1968.

LLOSA, Mario Vargas. La verdad de las mentiras. Barcelona: Seix Barral, 1990.

NITSCHACK, Horst. A hora da estrela e primera muerte de María (Jorge Eduardo Eielson): superação de uma estética da mimesis. In: PONTIERI, Regina (org.) Leitores e leituras de Clarice Lispector. São Paulo: 2004, p. 213-234.

ROSA, Guimarães. Sagarana. $4^{a}$ ed. Rio de Janeiro: José Olympio, 1956.

SANTOS, Boaventura Souza. Pela mão de Alice: o social e o político na pós-modernidade. 3 ed. São Paulo: Cortez, 1997.

SEVCENKO, Nicolau. Metrópole: matriz da lírica moderna. In: PECHMAN, Robert Moses. Olhares sobre a cidade. Rio de Janeiro: Ed. UFRJ, 1994. 